\title{
1978 DEC user group report
}

\author{
DORIS AARONSON \\ New York University, New York, New York 10003
}

\begin{abstract}
The 1978 meeting of users/owners of Digital Equipment Corporation (DEC) computer equipment is discussed.
\end{abstract}

Many Digital Equipment Corporation (DEC) users are modernizing their computer laboratories by switching from PDP-8 and -12 computers to PDP-11. Hence, they are involved in purchasing decisions for entirely new systems and for new peripherals. In addition, large numbers of researchers are developing computer laboratories for the first time. This surge of new purchasing is occurring in part because many experienced computer owners/users have had computer laboratories for about 10 years, and these labs have become economically inefficient. Some peripherals, for example, visual displays, electromechanical terminals, and A/D converters, are beginning to break down. But, the more pressing reason for new purchases is that the cost of service contracts on the older equipment is often double that for far more powerful new equipment. With the sharply decreasing equipment costs for new hardware, particularly for microprocessors, past users are switching hardware. Also, young investigators are now finding that computer labs do not cost much more than traditional labs, and they offer speed, flexibility, and reliability that noncomputer hardware does not have.

This year's meeting was user motivated in order to provide useful information and decision criteria for the new hardware purchases. The individual speakers have all been involved in developing new DEC computer labs themselves during the past year or so. They have put forth the reasons for purchasing small machines, such as the PDP-11/03 or the PDP-11/34, which often communicate with large university computer centers when additional capacity is needed (Grupsmith \& Ferres, 1979). Alternatively, the reasons for developing larger self-sufficient systems, such as the PDP-11/45, 55, 60, and 70 , were presented by Aaronson, based on discussions with Hollan, whose ideas are printed elswhere in this issue (Waller \& Hollan, 1979). Regarding vendor decisions, Aaronson (1979) presents the results of a user survey on purchases of DEC-compatible equipment from non-DEC vendors. The Digital Equipment Corporation representative, Mullen, discussed DEC's latest improvements in hardware, software, and service. Mullen's remarks are not printed as part of this symposium, as much of that information appears in his paper presented in Session II, "The LSI-1 1 Laboratory System."

The enthusiastic and opinionated user discussions make it clear that there are no "majority" opinions on how to make these new purchasing decisions. Rather, each user has particular research needs and economic constraints, and what is right for one user may not be for the next. In light of this situation, this DEC User Group can best serve the needs of current members if experienced users provide information on past purchases and experiences. The discussions provided helpful details in this direction. In addition, members of the DEC User Group are available to help new purchasers who might want to contact them throughout the year. A list of names, addresses, and phone numbers of recent purchasers of DEC-compatible equipment from nonDEC vendors can be obtained by writing to Doris Aaronson. These users specifically checked a box on the survey form indicating that they are willing to help others with purchasing information. Aaronson (1978, p. 298) lists DEC "computer friends" who are willing to help new computer users. Finally, Steve Mullen, the DEC representative for Life Science Application is up to date on DEC products and services. He has generally been quite helpful to our users, and he is willing to obtain information requested by users and to return phone calls. Interested persons should write Mullen at 200 Forrest Street, Marlborough, Massachusetts 01752 (Mail Stop MR2-3/M84) or phone (617) 481-9511.

\section{REFERENCES}

AARonson, D. DEC users' group report. Behavior Research Methods \& Instrumentation, 1978, 10, 297-299.

AARONSON, D. DEC vs. DEC-compatible hardware. Behavior Research Methods \& Instrumentation, 1979, 11, 159-162.

Grupsmith, E., \& Ferres, S. Minicomputer labs that talk to maxicomputers. Behavior Research Methods \& Instrumentation, 1979, 11, 156-158.

Wallen, M. R., \& Hollan, J. D. The LNR laboratory. Behavior Research Methods \& Instrumentation, 1979, 11, 151-155. 